\title{
ESTATE TAXATION WITH BOTH ACCIDENTAL AND PLANNED BEQUESTS
}

\author{
PIERRE PESTIEAU \\ MOTOHIRO SATO
}

\section{CESIFO WORKING PAPER NO. 1799 \\ CATEGORY 1: PuBliC FinANCE \\ SEPTEMBER 2006}

Presented at CESifo Venice Summer Institute, Workshop on

“The Future of CAPITAl InCOME TAXATION”, July 2006

An electronic version of the paper may be downloaded

- from the SSRN website:

- from the RePEc website:

wWw.SSRN.com

- from the CESifo website:

www.RePEc.org

www.CESifo-group.de 


\title{
ESTATE TAXATION WITH BOTH ACCIDENTAL AND PLANNED BEQUESTS
}

\begin{abstract}
Actual inheritances are an hybrid of canonical types of bequests and in particular of accidental bequests and altruistic bequests. In this paper, bequeathed estate consists of two components: an amount intended by altruistic parents and an amount which results from the "premature" death of parents. Altruistic parents can also invest in their children's education. Taxing those two types of bequests separately is known to have different implications. The purpose of this paper is to see the distributive incidence of estate taxation when those two components are indistinguishable. The substitutability between education and intended bequests plays a key role in the tax design.
\end{abstract}

JEL Code: H20, D64.

Keywords: estate taxation, inheritance, bequests motives.

\author{
Pierre Pestieau \\ CREPP, University of Liège \\ Bd du Rectorat 7 \\ 4000 Liège \\ Belgium \\ p.pestieau@ulg.ac.be
}

\author{
Motohiro Sato \\ Hitotsubashi University \\ 2-1 Naka, Kunitachi \\ Tokyo 186-8601 \\ Japan \\ ce00589@srv.cc.hit-u.ac.jp
}

September 20, 2006

The second author is grateful for financial support of the Center of Excellence Project of the Ministry of Education of Japan. 


\section{Introduction}

Nobody likes paying taxes especially when he is dead. More today than yesterday it would seem. An increasing number of countries are without an inheritance or an estate tax and some, including the United States, contemplate to phase it out in the near future. This is a bit surprising for a tax long thought are the most efficient and the most equitable. For a number of social philosophers and classical economists estate or inheritance tax is the ideal tax: it is highly progressive and it has few disincentives effects since it is only payable at death and it is fair since it concerns unearned resources. Yet, opponents of the "death tax" as they have dubbed it claim that it is unfair and immoral. It penalizes the frugal and loving parents who pass wealth on to their children, reducing incentive to save and to invest.

Why so much controversy? One of the reasons is that there are different types of bequests, more precisely different reasons to leave bequests and for each of them the social desirability of a tax may vary. For example, the advocates of estate taxation have often in mind accidental bequests the taxation of which is supposed to be harmless. Opponents of the death tax focus on altruistic bequests and the disincentive effects of taxing them. They also claim that it prevents small business from passing from generation to generation.

The purpose of this paper is to assess the desirability of estate taxation when bequests result from lifetime uncertainty and from a mere joy of giving. ${ }^{1}$ In the absence of private annuity market uncertainty about the length of life leads to some unexpected bequests. At the same time, parents may very well draw joy from giving some wealth (human and physical) to their children. These two types of bequests - accidental bequests and bequests based on the joy of giving - are known to have different implications and particularly to react to taxation in contrasting ways. ${ }^{2}$ If they could be distinguished they should be taxed differently. Unfortunately they cannot be distinguished and this makes the problem of estate taxation quite difficult. Not surprisingly its incidence is highly sensitive to the relative importance of the two bequest motives.

To study this issue we use a two-period overlapping generations (OLG) growth model cast in a closed economy. There is some idiosyncratic uncertainty on the length of life in the second-period and there is no annuity markets. This leads to accidental bequests and to a certain heterogeneity among individuals. If there was no joy of giving and individuals had the

\footnotetext{
${ }^{1}$ This paper is an outgrowth of an earlier paper by Michel and Pestieau (2002). Philippe Michel suddenly passed away during the Summer 2004.

${ }^{2}$ For an overview see Cremer and Pestieau (2005), Kaplow (2001).
} 
same labor productivity, the standard result is that a $100 \%$ tax on accidental bequests has no adverse effects on efficiency but can contribute to more equity. There is another source of bequests. Parents leave part of their saving to their children out of some joy of giving. This type of bequests can take two forms: education spending and financial bequest. As shown by Becker and Tomes (1979) investment in education has the priority as long as its marginal return exceeds the rate of interest. Education spending is not directly taxed unlike intended financial bequest. This taxation is likely to have some effect on the level of capital accumulation (positive or negative depending on the intertemporal elasticity of substitution). In this paper we are concerned by the effect of estate taxation on the coefficient of variation of lifetime income and on average income. In other words we are not concerned by the optimal taxation issue but rather by the marginal effect of estate taxation on what is considered as a reasonable index of inequality. The reason of this choice (coefficient of variation rather than social welfare function and tax reform rather than optimal taxation) is one of analytical simplicity. Even within this single specification the problem happens to be difficult.

Another source of heterogeneity is productivity. Individuals have different productivities which can be or not correlated across generations, but which are statistically independent of lifetime uncertainty. We will see that the desirability of an estate tax increase depends on the relative importance of accidental and intended bequest, the balance between educational investment and intended financial bequest and the extent of intergenerational mobility.

Michel and Pestieau (2002) consider a much simpler version of this model. In their paper the only source of heterogeneity is lifetime uncertainty. Individuals have the same productivity. Preferences and technology are homothetic and strictly concave. There is no transmission of human capital. If estate taxes could be distinguished according to the bequest motive, the tax on accidental bequest would always be desirable (i.e. it would lower the coefficient of variation without depressing average output). ${ }^{3}$ The tax on intended bequests is only desirable when the intertemporal elasticity of substitution is less than or equal to 1 . When it is higher than 1 , the reduction in capital accumulation can more than outweigh the reduction in inequality. When the two taxes are merged, there is a value of the elasticity of substitution higher than 1 above which the tax is undesirable.

\footnotetext{
${ }^{3}$ The conventional wisdom that accidental bequests if they could be taxed separably should be subject to a $100 \%$ tax has be recently challenged by Blumkin and Sadka (2004) who show that in an optimal income tax setting à la Mirrlees leaving some accidental bequests untaxed can be desirable as it relaxes the self-selection constraints. In our model, there is no optimal taxation and intended bequests come from the joy of giving and not from pure altruism.
} 
In this paper we introduce productive heterogeneity and intergenerational mobility. We also look at the impact of alternative taxes on the coefficient of variation and on the mean of income. There is a price to pay for this generalization: we can only use log-linear utilities and Cobb-Douglas production functions.

The rest of the paper is organized as follows. In section 2 the basic OLG model is introduced with the steady-state values of capital accumulation, aggregate production and human capital. In section 3 we turn to the calculation of the coefficient of variation of life-time income and analyze the effects of alternative tax tools on the steady-state value of this coefficient. Section 4 combines the tax incidence on both average income and inequality to evaluate the welfare incidence of tax policies and particularly of estate taxes. A final section concludes.

\section{The model}

\subsection{Consumers}

To deal with the problem at hand we adopt a standard OLG model with lifetime uncertainty. Individuals belonging to generation $t$ and of productivity $i$ live for two periods. They work and earn $w_{t} h_{t}^{i}$ in the first with $w_{t}$ being the standard wage rate and $h_{t}^{i}$ an index of human capital. They also inherit $b_{t}^{i}$ at the beginning of this period. They then devote their resources, $w_{t} h_{t}^{i}+b_{t}^{i}$, to present consumption $c_{t}^{i}$, educational investment $e_{t+1}^{i}$, and saving $s_{t}^{i} ; e_{t+1}^{i}$ serves to enhance the productivity of the next generation's worker. Saving is then devoted to consumption $d_{t+1}^{i}$ in their retirement period and to some intentional bequest $x_{t+1}^{i}$. We assume zero population growth which implies that each parent has only one child.

Uncertainty in the length of lifetime is captured by assuming that each individual lives with certainty the entire first period but that they either live for the entire second period with probability $(1-\pi)$ or die prematurely at the beginning of the second period with probability $\pi$. Probably $\pi$ is the same for all generations; its value is common knowledge.

Individual type is defined by an ability parameter $a_{t}^{i}$ which combined with some education investment $e_{t}^{i}$ supplied by altruistic parents generates the level of human capital $h_{t}^{i}$ with

$$
h_{t}^{i}=h\left(a_{t}^{i}, e_{t}^{i}\right) .
$$

As already mentioned we use a Cobb-Douglas function and then

$$
h_{t}^{i}=\left(a_{t}^{i}\right)^{\mu}\left(e_{t}^{i}\right)^{1-\mu} \quad 0<\mu \leqslant 1 .
$$


The distribution of $a_{t}^{i}$ is time invariant with unitary mean $\bar{a}=1$ and variance $\sigma_{a}^{2}$. If there is perfect correlation between parent's and child's ability, both have the same type; otherwise, a child of type $i$ does not necessarily inherit from a parent with the same productivity. We will denote this intergenerational correlation by $\varrho$.

Individuals preferences are represented by a log-linear utility function with three arguments: $c_{t}^{i}, d_{t+1}^{i}, I_{t+1}^{i}$, namely, first period consumption, second period consumption and total intended transfers to children. We write:

$$
U_{t}^{i}=\log c_{t}^{i}+(1-\pi) \tilde{\beta} \log d_{t+1}^{i}+\gamma \log I_{t+1}^{i}
$$

where $\tilde{\beta}$ and $\gamma$ are parameters reflecting time preference and altruism respectively. For simplicity reasons, we use the notation $\beta=\tilde{\beta}(1-\pi)$, the product of time preference and survival probability.

In this setting financial bequests consist of an unintended part, the second period consumption of a parent who prematurely died and an intended part, $x_{t+1}$. There are two ways of bequeathing voluntarily: by investing in education, $e_{t+1}$ or by leaving $x_{t+1}$. Note that the argument of the utility function is $x_{t+1}$, that is after tax bequest as we show below. An individual of type $i$ and belonging to generation $t$ receives from his parent $e_{t}^{i}$ which implies an effective wage $h_{t}^{i} w_{t}$; he also receives $b_{t}^{i}=x_{t}^{i}$ if his parent lives through the second period or $b_{t}^{i}=x_{t}^{i}+d_{t}^{i}$ if his parent dies. From now on, we will use a second superscript $j=1,2$ for this. Individuals are thus characterized by their ability $i$, their generation $t$ and whether or not they benefit from accidental bequest $\left(j=1\right.$ or 2 ). The same individual intentionally leaves $x_{t+1}^{j i}$ and $e_{t+1}^{j i}$ taking into account the effects of these two transfers on the expected income of his child:

$$
I_{t+1}^{j i}=x_{t+1}^{j i}+\theta w_{t+1} h\left(e_{t+1}^{j i}, a_{t+1}^{i}\right)
$$

where $\theta$ denotes the (subjective) weight given to human capital relative to physical capital. As a benchmark, $\theta=1$, but we allow for the possibility that education receives more or less weight than physical bequest. In our formulation, individuals derive some joy of giving from intentional transfers, but not from the accidental one, if any. This is the consequence of our specification of paternalistic altruism.

The budget constraints for individuals belonging to generation $t$ and type $i$ are simply:

$$
\omega_{t}^{j i}=w_{t} h_{t}^{i}+b_{t}^{j i}=c_{t}^{j i}+s_{t}^{j i}+e_{t+1}^{j i}
$$

and

$$
R_{t+1} s_{t}^{j i}=d_{t+1}^{j i}+x_{t+1}^{j i}
$$


where $\omega_{t}^{j i}$ is the lifetime income, $s_{t}^{j i}$, saving. The subscript $j=1,2$ denotes whether or not there is unexpected bequest. $R_{t+1}$ is one plus the rate of interest. Both $R$ and $w$ are to be determined by the productive side of the model.

Although formally modelled as a two-periods model, we have in fact three overlapping generations. In period $t$ we have the working generation $t$, the surviving retired generation $t-1$ and the generation $t+1$ of children who have a passive role and receive an amount $e_{t+1}$ of education from their parents.

Figure 1: Intergenerational transfers

\begin{tabular}{lccc}
\hline \multicolumn{1}{r}{ Period $t-1$} & $t$ & $t+1$ \\
Generation & & & \\
$t-1$ & & $d_{t}$ & \\
$t$ & & $\mathrm{~d}_{t+1}$ & $\mathrm{x}_{\mathrm{t}+1}$ \\
$\mathrm{~d}_{\mathrm{t}+1}$
\end{tabular}

Figure 1 depicts the intergenerational flows $x_{t}, e_{t}$ and $d_{t}$ (with probability $\pi$ ). Education $e_{t+1}$ is transferred to $t+1$ generation at period $t$ and bequest $x_{t+1}$ is given at period $t+1$.

\subsection{Taxes and transfers}

Let us now introduce alternative taxes. First we have a wage tax, $\tau_{w}$, and a capital tax, $\tau_{r}$. Then we have an estate tax that is denoted $\tau_{b}$, but for the sake of presentation we also distinguish a tax on intended bequest $\tau_{x}$ and a tax on unintended bequest, $\tau_{u}$. The government also makes a uniform lump-sum transfer $T$ to the young generation. There is no public debt: tax revenue finances this uniform transfer. We posit time-invariant tax rates; only $T_{t}$ depends on time to satisfy the revenue constraint.

We now rewrite the above budget constraint:

$$
\begin{gathered}
\omega_{t}^{j i}=b_{i t}^{j i}+w_{t}\left(1-\tau_{w}\right) h_{t}^{j i}+T_{t}=c_{t}^{j i}+s_{t}^{j i}+e_{t+1}^{j i} \\
R_{t+1}\left(1-\tau_{r}\right) s_{t}^{j i}=d_{t+1}^{j i}+\left(1+\tau_{x}\right) x_{t+1}^{j i}
\end{gathered}
$$

where

$$
b_{t}^{1 i}=x_{t}^{i}+\frac{d_{t}^{i}}{1+\tau_{u}} \text { and } b_{t}^{2 i}=x_{t}^{i}
$$


Combining these two constraints, we obtain:

$$
\omega_{t}^{j i}=c_{t}^{j i}+e_{t+1}^{j i}+\frac{d_{t+1}^{j i}+x_{t+1}^{j i}\left(1+\tau_{x}\right)}{R_{t+1}\left(1-\tau_{r}\right)} .
$$

With these taxes, (2) becomes

$$
I_{t+1}^{j i}=x_{t+1}^{j i}+\theta w_{t+1}\left(1-\tau_{w}\right) h_{t+1}^{j i}
$$

We can now turn to the choice of an individual belonging to generation $t$, of type $i$ and having or not received an accidental bequest. It amounts to maximize (1) subject to (2) and (3) with respect to $c_{t}^{j i}, d_{t+1}^{j i}, x_{t+1}^{j i}$ and $e_{t+1}^{j i}$. Assuming interior solutions for these 4 variables, we obtain the following demand and supply functions:

$$
\begin{gathered}
c_{t}^{j i}=\frac{1}{1+\beta+\gamma}\left[\omega_{t}^{j i}+\theta \mu \frac{w_{t+1}}{R_{t+1}} q h_{t}^{j i}\right] \\
d_{t+1}^{j i}=\frac{\beta R_{t+1}\left(1-\tau_{r}\right)}{1+\beta+\gamma}\left[\omega_{t}^{j i}+\theta \mu \frac{w_{t+1}}{R_{t+1}} q h_{t+1}^{j i}\right] \\
x_{t+1}^{j i}=\frac{\gamma R_{t+1} z}{1+\beta+\gamma}\left[\omega_{t}^{j i}+\theta \mu \frac{w_{t+1}}{R_{t+1}} q h_{t+1}^{j i}\right]-z \theta w_{t+1} q h_{t+1}^{j i} \\
e_{t+1}^{j i}=\theta q w_{t+1} h_{t+1}^{j i} \frac{1-\mu}{R_{t+1}}=a_{t+1}^{i}\left(\theta q(1-\mu) \frac{w_{t+1}}{R_{t+1}}\right)^{1 / \mu}
\end{gathered}
$$

where $z=\frac{1-\tau_{r}}{1+\tau_{x}}$ and $q=\frac{1-\tau_{w}}{z}$.

These two parameters $z$ and $q$ can easily be interpreted. They represent the tax wedge that distorts the choice of intended bequests relative to consumption and the choice of education relative to intended bequest. The consumer's price of intended bequest is $\frac{1+\tau_{x}}{\left(1-\tau_{r}\right) R}=\frac{1}{z R}$. Another way to express this it is to say that the effective tax on intended bequests is $1-z=\frac{\tau_{x}+\tau_{r}}{1+\tau_{x}}$. In choosing between education and intended bequests (assumed to be positive), the parent equates their respective rate of return: $R z$ and $w\left(1-\tau_{w}\right) \frac{\partial h}{\partial e}$. The ratio of these rates of return is simply:

$$
w \frac{\frac{\partial h}{\partial e}\left(1-\tau_{w}\right)}{R z}=q \frac{w}{R} \frac{\partial h}{\partial e} .
$$

With the log-linear utilities and Cobb-Douglas education function, $c, d$ and $e$ are necessarily positive. As to $x$, it could be negative; this is why one 
generally assumes non negative bequests. Here to keep the problem simple, we even assume that $x$ is positive. Later we provide the necessary condition for this to hold.

\subsection{Production}

The production sector is summarized by a profit maximizing firm with a Cobb-Douglas production function:

$$
Y_{t}=A K_{t}^{\alpha} \bar{h}_{t}^{1-\alpha}
$$

where $Y_{t}$ is aggregate output, $K_{t}$, the capital stock and $\bar{h}_{t}$, aggregate human capital. Population $N$ is constant and normalized to 1 . Consequently, aggregate output and per capita output are equal.

We assume total depreciation after 1 period. Profit maximization implies

$$
R_{t}=\alpha Y_{t} / K_{t} \quad \text { and } \quad w_{t}=(1-\alpha) Y_{t} / \bar{h}_{t}
$$

where $w_{t}$ is the wage rate per efficiency unit. For further use, we write:

$$
k_{t}=K_{t} / \bar{h}_{t}
$$

Capital accumulation with total depreciation is equal to aggregate saving:

$$
K_{t+1}=\bar{s}_{t} .
$$

Both saving and human capital can be obtained from individual choices. We can show that saving is motivated by two objectives: second period consumption $(\beta)$ and intended bequest $(\gamma)$. Thus, using (4) and (5), we write:

$$
s_{t}^{j i}=\frac{\beta+\gamma}{1+\beta+\gamma}\left(\omega_{t}^{j i}+\theta \mu \frac{w_{t+1}}{R_{t+1}} q h_{t+1}^{j i}\right)-\theta \frac{w_{t+1}}{R_{t+1}} q h_{t+1}^{j i} .
$$

Summing up over all individuals $j i$ one obtains:

$$
K_{t+1}=\bar{s}_{t}=\frac{\beta+\gamma}{1+\beta+\gamma}\left[\bar{\omega}_{t}+\theta \mu \frac{w_{t+1}}{R_{t+1}} q \bar{h}_{t+1}\right]-\theta \frac{w_{t+1}}{R_{t+1}} q \bar{h}_{t+1} .
$$

By rearranging this expression, we obtain a relation between $\bar{\omega}_{t}$ and $K_{t+1}$ :

$$
\frac{1}{1+\beta+\gamma}\left[\bar{\omega}_{t}+\theta \mu \frac{w_{t+1}}{R_{t+1}} q \bar{h}_{t+1}\right]=\frac{1}{\beta+\gamma}\left[K_{t+1}+\theta \frac{w_{t+1}}{R_{t+1}} q \bar{h}_{t+1}\right] .
$$

In the same way, we aggregate education and then the resulting human capital. We use (6) to obtain:

$$
\bar{e}_{t+1}=\left(\theta q(1-\mu) \frac{1-\alpha}{\alpha} k_{t+1}\right)^{1 / \mu}
$$


and hence

$$
\bar{h}_{t+1}=\left(\frac{1-\alpha}{\alpha}(1-\mu)\right)^{\frac{1-\mu}{\mu}}(\theta q)^{\frac{1-\mu}{\mu}} k_{t+1}^{\frac{1-\mu}{\mu}} .
$$

It is important to understand the dynamics of this model. At the start of period $t$, an individual of productivity $i$ inherit either $b_{t}^{1 i}$ or $b_{t}^{2 i}$ depending on whether or not his parent belonging to generation $t-1$ and being of type $i$ dies prematurely. In other words it is important to distinguish $(i, t-1)$ from $(i, t)$.

\subsection{Bequests and life-time income}

It is now time to introduce the two types of bequests. In case of early death of his parents of ability $i$, a child inherit

$$
\begin{aligned}
b_{t+1}^{1 i} & =x_{t+1}^{i}+\frac{d_{t+1}^{i}}{1+\tau_{u}} \\
& =z R_{t+1} \frac{\gamma+\beta \varphi}{1+\beta+\gamma}\left(\omega_{t}^{i}+\theta \mu \frac{w_{t+1}}{R_{t+1}} q h_{t+1}^{i}\right)-z \theta q w_{t+1} h_{t+1}^{i}(10
\end{aligned}
$$

In case of late death, inheritance is exclusively intended:

$$
\begin{aligned}
b_{t+1}^{2 i} & =x_{t+1}^{i} \\
& =z R_{t+1} \frac{\gamma}{1+\beta+\gamma}\left(\omega_{t}^{i}+\theta \mu \frac{w_{t+1}}{R_{t+1}} q h_{t+1}^{i}\right)-z \theta q w_{t+1} h_{t+1}^{i}
\end{aligned}
$$

where $\varphi \equiv \frac{1+\tau_{x}}{1+\tau_{u}}=1$ when the two types of bequests are undistinguished $\left(\tau_{x}=\tau_{u}=\tau_{b}\right)$.

As already mentioned we assume that $x_{t+1}^{i}>0$. For further use, we now write the average levels of bequests:

$$
\begin{gathered}
\bar{b}_{t+1}^{1}=z R_{t+1} \frac{\gamma+\beta \varphi}{1+\beta+\gamma}\left(\bar{\omega}_{t}+\theta \mu \frac{w_{t+1}}{R_{t+1}} q \bar{h}_{t+1}\right)-z \theta q w_{t+1} \bar{h}_{t+1} \\
\bar{b}_{t+1}^{2}=\bar{b}_{t+1}^{1}-z R_{t+1} \frac{\beta \varphi}{1+\beta+\gamma}\left(\bar{\omega}_{t}+\theta \mu \frac{w_{t+1}}{R_{t+1}} q \bar{h}_{t+1}\right)
\end{gathered}
$$

Using (7) average inherited wealth can be rewritten:

$$
\bar{b}_{t+1}^{1}=z R_{t+1} \frac{\gamma+\beta \varphi}{\gamma+\beta}\left[K_{t+1}+\theta \frac{w_{t+1}}{R_{t+1}} q \bar{h}_{t+1}\right]-z \theta q w_{t+1} \bar{h}_{t+1}
$$


and

$$
\bar{b}_{t+1}^{2}=\bar{b}_{t+1}^{1}-z R_{t+1} \frac{\beta \varphi}{\gamma+\beta}\left[K_{t+1}+\theta \frac{w_{t+1}}{R_{t+1}} q \bar{h}_{t+1}\right] .
$$
Thus,

From the Cobb-Douglas assumption, $R K=\alpha Y$ and $w \bar{h}=(1-\alpha) Y$.

$$
\bar{b}_{t+1}^{1}=\alpha z \frac{\beta \varphi+\gamma}{\beta+\gamma} Y_{t+1}-\frac{\beta(1-\varphi)}{\beta+\gamma}\left(1-\tau_{w}\right)(1-\alpha) Y_{t+1} \theta
$$

and

$$
\bar{b}_{t+1}^{2}=\alpha z \frac{\gamma}{\beta+\gamma} Y_{t+1}-\frac{\beta}{\beta+\gamma}\left(1-\tau_{w}\right)(1-\alpha) Y_{t+1} \theta
$$

As we assume that $\bar{b}_{t+1}^{2}=\bar{x}_{t+1}>0$, we have: $\frac{\alpha \gamma}{1-\alpha}>\beta q \theta$.

Depending on the death of his parent, a child of ability $i$ will have an income $\omega_{t}^{1 i}$ or $\omega_{t}^{2 i}$. More precisely, making use of (10.1) and (10.2),

$$
\begin{gathered}
\omega_{t}^{j i}=b_{t}^{j i}+w_{t}\left(1-\tau_{w}\right) h_{t}^{i}+T_{t .} \\
\omega_{t}^{1 i}=z R_{t} \frac{\gamma+\beta \varphi}{1+\beta+\gamma}\left[\omega_{t-1}^{i}+\theta \mu \frac{w_{t}}{R_{t}} q h_{t}^{i}\right]+(1-\theta) z q w_{t} h_{t}^{i}+T_{t} \\
\omega_{t}^{2 i}=z R_{t} \frac{\gamma}{1+\beta+\gamma}\left[\omega_{t-1}^{i}+\theta \mu \frac{w_{t}}{R_{t}} q h_{t}^{i}\right]+(1-\theta) z q w_{t} h_{t}^{i}+T_{t} .
\end{gathered}
$$

In aggregate terms, we write

$$
\bar{\omega}_{t}=\pi \bar{\omega}_{t}^{1}+(1-\pi) \bar{\omega}_{t}^{2}=\bar{b}_{t}^{2}+\pi\left(\bar{b}_{t}^{1}-\bar{b}_{t}^{2}\right)+\left(1-\tau_{w}\right) w_{t} \bar{h}_{t}+T_{t} .
$$

Using equations (11.1) and (11.2) for $\bar{b}_{t}^{j}$ and the revenue constraint:

$$
T_{t}=\tau_{x} \bar{b}_{t}^{2}+\tau_{u} \pi\left(\bar{b}_{t}^{1}-\bar{b}_{t}^{2}\right)+\tau_{w} w_{t} \bar{h}_{t}+\tau_{r} R_{t} K_{t},
$$

we have:

$$
\bar{\omega}_{t}=\left(1+\tau_{x}\right) \bar{b}_{t}^{2}+\pi\left(1+\tau_{u}\right)\left(\bar{b}_{t}^{1}-\bar{b}_{t}^{2}\right)+w_{t} \bar{h}_{t}+\tau_{r} R_{t} K_{t},
$$

which can also be written as:

$$
\bar{\omega}_{t}=Y_{t}\left[1-\frac{\beta}{\beta+\gamma}(1-\pi)\left(1-\tau_{r}\right)(\alpha+(1-\alpha) q \theta)\right] .
$$

It is interesting to observe that average lifetime income and average output don't coincide with or without taxation. Without tax and with $\theta=1$ one has:

$$
\bar{\omega}_{t}=Y_{t}\left(\frac{\gamma+\beta \pi}{\gamma+\beta}\right)<Y_{t}
$$


Another way of presenting this difference is to write:

$$
\bar{\omega}_{t}=Y_{t}-(1-\pi) \bar{d}_{t}<Y_{t}
$$

where $\bar{d}_{t}$ is the average consumption of the old at period $t$. It should be noted that in the present model, life-time income is income accruing to the young generation.

\subsection{Capital accumulation}

With full depreciation, saving is equal to the capital stock used in the next period.

$$
s_{t}=K_{t+1}=\frac{\beta+\gamma}{1+\beta+\gamma} \bar{\omega}_{t}-\left(1-\frac{\beta+\gamma}{1+\beta+\gamma} \mu\right) \theta q \frac{1-\alpha}{\alpha} K_{t+1}
$$

Substituting (16), we establish the following:

$$
\begin{aligned}
& K_{t+1}\left[1+\frac{1-\alpha}{\alpha} \theta q\left(1-\frac{\beta+\gamma}{1+\beta+\gamma} \mu\right)\right] \\
= & \frac{Y_{t}}{1+\beta+\gamma}\left[\beta+\gamma-\beta(1-\pi)\left(1-\tau_{r}\right)(\alpha+(1-\alpha) q \theta)\right]
\end{aligned}
$$

\subsection{Steady state}

We now turn to the steady-state solutions to which the economy converges. Dropping the time index $t$, we rewrite (9) and (17):

$$
\begin{gathered}
\bar{h}=\left[\frac{1-\alpha}{\alpha}(1-\mu)\right]^{\frac{1-\mu}{\mu}} \theta q^{\frac{1-\mu}{\mu}} k^{\frac{1-\mu}{\mu}} \\
k^{1-\alpha}=\frac{A}{1+\beta+\gamma} \frac{\beta+\gamma-\beta(1-\pi)\left(1-\tau_{r}\right)(\alpha+(1-\alpha) q \theta)}{1+\frac{1-\alpha}{\alpha} \theta q\left(1-\frac{\beta+\gamma}{1+\beta+\gamma} \mu\right)} .
\end{gathered}
$$

From (19) we have $k=k\left(q, \tau_{r}\right)$ with $\frac{\partial k}{\partial \tau_{r}}>0$ and $\frac{\partial k}{\partial q}<0$. This in turn implies that $\frac{\partial R}{\partial \tau_{r}}<0$ and $\frac{\partial R}{\partial q}>0$.

We then obtain output in the steady-state:

$$
Y=A k^{\alpha} \bar{h}=A\left[\frac{1-\alpha}{\alpha}(1-\mu) \theta q\right]^{\frac{1-\mu}{\mu}} k^{\frac{1-\mu}{\mu}+\alpha} .
$$


For further use, let us differentiate $\log \left(Y=\right.$ constant $+\frac{1-\mu}{\mu} \log q$ $\left.+\left(\alpha+\frac{1-\mu}{\mu}\right) \log k\right)$ with respect to $q$. This yields:

$$
\begin{aligned}
\frac{d \log Y}{d q}= & \frac{1-\mu}{\mu q}-\left(\alpha+\frac{1-\mu}{\mu}\right)\left\{\frac{\beta(1-\pi)\left(1-\tau_{r}\right) \theta}{\beta+\gamma-\beta(1-\pi)\left(1-\tau_{r}\right)(\alpha+(1-\alpha) \theta q)}\right. \\
& \left.+\frac{\theta\left(1-\frac{\beta+\gamma}{1+\beta+\gamma-\mu}\right)}{\alpha+(1-\alpha) \theta\left(1-\frac{\beta+\gamma}{1+\beta+\gamma} \mu\right) q}\right\} .
\end{aligned}
$$

Assuming that $\log Y$ is strictly concave, we have that $Y$ is a single-peaked function of $q$ with maximum at $q^{*}$. We thus have:

$$
\begin{gathered}
Y=Y\left(q, \tau_{r}\right) \\
+/-+
\end{gathered}
$$

The intuition is straightforward. For $q<q^{*}$, enhancing the human capital relative to the physical one is desirable; it is growth promoting to raise $q$, namely lowering $\tau_{w}$ relative to $\tau_{x}$ and $\tau_{r}$. The opposite occurs once we reach $q>q^{*}$. The reason why capital tax $\tau_{r}$ is raising $Y$ is that in the present model we suppose that the collected tax revenue is transferred to the young who save.

\section{Coefficient of variation}

We now turn to the coefficient of variation of the life-time income which is going to be our measure of inequality.

From (12.1), (12.2) and (10.1), (10.2), we write:

$$
\bar{\omega}_{t+1}^{1}-\bar{\omega}_{t+1}^{2}=\bar{b}_{t+1}^{1}-\bar{b}_{t+1}^{2}=\frac{\beta \varphi}{\beta+\gamma}\left(\alpha z+\left(1-\tau_{w}\right)(1-\alpha) \theta\right) Y_{t+1} .
$$

We also compute the deviations from the mean:

$$
\begin{aligned}
& \omega_{t+1}^{1 i}-\bar{\omega}_{t+1}^{1}=z R_{t+1} \frac{\gamma+\beta \varphi}{1+\beta+\gamma}\left(\omega_{t}^{i}-\bar{\omega}_{t}^{1}\right)+\left(1-\tau_{w}\right) w_{t+1}\left(1-\theta+\theta \mu \frac{\gamma+\beta \varphi}{1+\beta+\gamma}\right)\left(a_{t+1}^{i}-1\right) \bar{h}_{t+1} \\
& \omega_{t+1}^{2 i}-\bar{\omega}_{t+1}^{2}=z R_{t+1} \frac{\gamma}{1+\beta+\gamma}\left(\omega_{t}^{i}-\bar{\omega}_{t}^{2}\right)+\left(1-\tau_{w}\right) w_{t+1}\left(1-\theta+\theta \mu \frac{\gamma}{1+\beta+\gamma}\right)\left(a_{t+1}^{i}-1\right) \bar{h}_{t+1} .
\end{aligned}
$$

From these deviations, we calculate the variance of $\omega_{t+1}^{i}$ :

$$
\begin{aligned}
\operatorname{Var}\left(\omega_{t+1}^{i}\right)= & \pi E\left(\omega_{t+1}^{1 i}-\bar{\omega}_{t+1}^{1}\right)^{2}+(1-\pi) E\left(\omega_{t+1}^{2 i}-\omega_{t+1}^{2}\right)^{2} \\
& +\left[\pi(1-\pi)^{2}+(1-\pi) \pi^{2}\right]\left(\bar{\omega}_{t+1}^{1}-\bar{\omega}_{t+1}^{2}\right)^{2} .
\end{aligned}
$$


Using the above expressions, we obtain:

$$
\begin{aligned}
\operatorname{Var}\left(\omega_{t+1}^{i}\right)= & \operatorname{Var} \omega_{t}^{i}\left(\frac{z R_{t+1}}{1+\beta+\gamma}\right)^{2}\left(\pi(\gamma+\beta q)^{2}+(1-\pi) \gamma^{2}\right)+\sigma_{a}^{2}(1-\alpha)^{2}\left(1-\tau_{\omega}\right)^{2} Y_{t+1} \\
& {\left[\pi\left(1-\theta+\theta \mu \frac{\gamma+\beta \varphi}{1+\gamma+\beta}\right)^{2}+(1-\pi)\left(1-\theta+\theta \mu \frac{\gamma}{1+\beta+\gamma}\right)^{2}\right] } \\
& +2 z R_{t+1}\left(1-\tau_{w}\right)(1-\alpha) Y_{t+1} \operatorname{cov}\left(\omega_{t}^{i}, a_{t}^{i}\right) \frac{\varrho}{1+\beta+\gamma} \\
& {\left[\pi(\gamma+\beta \varphi)\left(1-\theta \mu \frac{\gamma+\beta \varphi}{1+\beta \gamma}\right)+(1-\pi) \gamma\left(1-\theta+\theta \mu \frac{\gamma}{1+\beta+\gamma}\right)\right] } \\
& +\pi(1-\pi)\left(\frac{\beta \varphi}{\beta+\gamma}\right)^{2}\left(\alpha z+\left(1-\tau_{w}\right)(1-\alpha) \theta\right)^{2} Y_{t+1}^{2} .
\end{aligned}
$$

In this expression we used the following results:

$$
\bar{\omega}_{t}=Y_{t}\left[1-\frac{\beta}{\beta+\gamma}(1-\pi)\left(1-\tau_{r}\right)(\alpha+(1-\alpha) q \theta)\right]
$$

and

$$
\begin{gathered}
\operatorname{cov}\left(\omega_{t+1}^{i}, a_{t+1}^{i}\right)=z R_{t+1} \frac{\gamma+\pi \beta \varphi}{1+\beta+\gamma} \varrho \operatorname{cov}\left(\omega_{t}^{i}, a_{t}^{i}\right) \\
+\left(1-\tau_{w}\right)(1-\alpha) \sigma_{a}^{2} Y_{t+1}\left(1-\theta+\theta \mu \frac{\gamma+\pi \beta \varphi}{1+\beta+\gamma}\right)
\end{gathered}
$$

where $\varrho$ is the correlation between $a_{t}^{i}$ and $a_{t+1}^{i}$, and $\sigma_{a}^{2}$ is the variance of $a_{t}^{i}$, which is time invariant.

In the steady-state, we can write:

$$
\operatorname{cov}\left(\omega^{i}, a^{i}\right)=\frac{1-\theta+\theta \mu \frac{\gamma+\pi \beta \varphi}{1+\beta+\gamma}}{1-\varrho \frac{\gamma+\pi \beta \varphi}{1+\beta+\gamma} z R}\left(1-\tau_{w}\right)(1-\alpha) \sigma_{a}^{2} Y .
$$

Hence we have

$$
\begin{gathered}
\frac{\operatorname{Var}(\omega)}{Y^{2}}\left[1-\left(\frac{z R}{1+\beta+\gamma}\right)\left(\pi(\gamma+\beta \varphi)^{2}+(1-\pi) \gamma^{2}\right)\right]= \\
\sigma_{a}^{2}(1-\alpha)^{2}\left(1-\tau_{w}\right)^{2}\left[\pi\left(1-\theta+\theta \mu \frac{\gamma+\beta \varphi}{1+\beta+\gamma}\right)^{2}+(1-\pi)\left(1-\theta+\theta \mu \frac{\gamma}{1+\beta+\gamma}\right)^{2}\right] \\
+\pi(1-\pi)\left(\frac{\beta \varphi}{\beta+\gamma}\right)^{2}\left(z \alpha+\left(1-\tau_{w}\right)(1-\alpha) \theta\right)^{2}+2 \frac{\varrho z R}{1+\beta+\gamma}\left(1-\tau_{w}\right)^{2}(1-\alpha)^{2} \sigma_{a}^{2} \\
\frac{1-\theta+\theta \mu \frac{\gamma+\pi \beta \varphi}{1+\beta+\gamma}}{1-\varrho \frac{\gamma+\pi \beta \varphi}{1+\beta+\gamma} z R}\left[\pi(\gamma+\beta \varphi)\left(1-\theta+\theta \mu \frac{\gamma+\beta \varphi}{1+\beta+\gamma}\right)+(1-\pi) \gamma\left(1-\theta+\theta \mu \frac{\gamma}{1+\beta+\gamma}\right)\right] .
\end{gathered}
$$


To obtain the coefficient of variation, we substitute (16) in (22):

$$
\begin{aligned}
& C V(\omega)\left[1-\frac{\beta}{\beta+\gamma}(1-\pi)\left(1-\tau_{r}\right)(\alpha+(1-\alpha) q \theta)\right]^{2} \\
& {\left[1-\left(\frac{z R}{1+\beta+\gamma}\right)^{2}\left(\pi(\gamma+\beta \varphi)^{2}+(1-\pi) \gamma^{2}\right)\right] } \\
= & \sigma_{a}^{2}(1-\alpha)^{2}\left(1-\tau_{w}\right)^{2}\left[\pi\left(1-\theta+\theta \mu \frac{\gamma+\beta \varphi}{1+\beta+\gamma}\right)^{2}+(1-\pi)\left(1-\theta+\theta \mu \frac{\gamma}{1+\beta+\gamma}\right)^{2}\right] \\
& +\pi(1-\pi)\left(\frac{\beta \varphi}{\beta+\gamma}\right)^{2}\left(\alpha z+\left(1-\tau_{w}\right)(1-\alpha) \theta\right)^{2}+\frac{2 \varrho}{1+\beta+\gamma}(1-\alpha)^{2}\left(1-\tau_{w}\right)^{2} \\
& \sigma_{a}^{2} \frac{z R}{1-\varrho z R \frac{\gamma+\pi \beta \varphi}{1+\beta+\gamma}}\left(1-\theta+\theta \mu \frac{\gamma+\pi \beta \varphi}{1+\beta+\gamma}\right)\left[\pi(\gamma+\beta \varphi)\left(1-\theta+\theta \mu \frac{\gamma+\beta \varphi}{1+\beta+\gamma}\right)\right. \\
& \left.+(1-\pi) \gamma\left(1-\theta+\theta \mu \frac{\gamma}{1+\beta+\gamma}\right)\right]
\end{aligned}
$$

After some manipulations one obtains an expression for the coefficient of variation of $\omega$ as a function of policy variables and $R$, itself a function of the policy variables $\left(\begin{array}{c}R\left(\underset{+}{q}, \tau_{r}\right) \\ +-\end{array}\right)$.

We denote the RHS of (22') by $\psi$ and the LHS after $C V(w)$ by $\Delta$. Then we have:

$$
C V(\omega)=\frac{\psi\left(\stackrel{+}{q}, \overline{\tau_{r}}, \overline{\tau_{w}}, \stackrel{+}{\varphi}, \stackrel{+}{z}\right)}{\Delta\left(q, \tau_{r}, \varphi, \underline{\varphi}\right)} .
$$

We thus observe that these five parameters have an unambiguous effect on $C V$ :

$$
C V(\omega)=C V\left(\underset{+}{q}, \tau_{r}, \tau_{w}, \underset{+}{\varphi}, z\right)
$$

where $z=\frac{1-\tau_{r}}{1+\tau_{x}}, q=\frac{1-\tau_{w}}{z}$ and $\varphi=\frac{1+\tau_{x}}{1+\tau_{u}}$.

Let us see what these price terms mean. First, there is $z=\left(1-\tau_{r}\right)\left(1-\frac{\tau_{x}}{1+\tau_{x}}\right)$ that represents the net of tax price of planned bequests. It normally includes both $\tau_{x}$ and $\tau_{r}$ that represents the double taxation of planned bequests. Then, there is $q$ that denotes the relative net-of-tax price of earnings relative to planned bequests. Finally, $\varphi$ represents the trade-off between planned and accidental bequests including the tax rates. When these rates cannot be distinguished, $\varphi=1$.

To assess the effect of these tax parameters on welfare and not just on inequality, we need to know their impact on per capita income. We have seen that $Y=Y\left(q, \tau_{r}\right)$. 
For tractability reasons we didn'nt use a social welfare function. We can however talk of an unambiguous increase in welfare if we have an increase in $Y$ combined with a decrease in $C V$. Consequently we can look at the effect of our price parameters on $C V, Y$ and social welfare.

Table 1: Welfare effect of price parameters

\begin{tabular}{lcccc}
\hline Effect of an increase of & $q$ & $\tau_{r}$ & $\varphi$ & $z$ \\
\hline & & & & \\
\hline on $C V$ & $(+)$ & $(-)$ & $(+)$ & $(+)$ \\
on $Y$ & $(+/-)$ & $(+)$ & $(0)$ & $(0)$ \\
on social welfare & $(? /-)$ & $(+)$ & $(-)$ & $(-)$
\end{tabular}

$$
\text { where } z=\frac{1-\tau_{r}}{1+\tau_{x}}, q=\frac{1-\tau_{w}}{z}=\frac{1-\tau_{w}}{1+\tau_{r}}\left(1+\tau_{x}\right) \text {. }
$$

Table 1 gives the direct effect of price parameters. For example, we observe that the direct effect of an interest income tax increase is welfare improving, but it has indirect effects on $z$ and $q$ that can change this conclusion. What is clear is that a relative increase in the tax on unplanned bequests ( $\varphi$ going down) is welfare improving.

\section{The incidence of taxes on welfare}

Unambiguity with respect to $q, \tau_{r}, \varphi$ and $z$ does not mean unambiguity towards the tax rates themselves. Starting with the coefficient of variation, let us consider the total effect of a given tax holding the other taxes (but T) constant:

$$
\begin{aligned}
\frac{d C V}{d \tau_{r}} & =\left[\frac{\partial C V}{\partial q} \frac{1-\tau_{w}}{z^{2}}-\frac{\partial C V}{\partial z}\right] \frac{1}{1+\tau_{x}}+\frac{\partial C V}{\partial \tau_{r}} \gtrless 0 \\
\frac{d C V}{d \tau_{x}} & =\left[\frac{\partial C V}{\partial q} \frac{1-\tau_{w}}{z^{2}}-\frac{\partial C V}{\partial z}\right] \frac{1-\tau_{r}}{\left(1+\tau_{x}\right)^{2}}+\frac{\partial C V}{\partial \varphi} \frac{1}{1+\tau_{u}} \gtrless 0 \\
\frac{d C V}{d \tau_{w}} & =-\frac{\partial C V}{\partial q} \frac{1}{z}<0 \\
\frac{d C V}{d \tau_{u}} & =-\frac{\partial C V}{\partial \varphi} \frac{1+\tau_{x}}{\left(1+\tau_{u}\right)}<0 .
\end{aligned}
$$

The effect of a tax on unintended bequests is not surprising. That of a wage tax is due to the absence of labor supply distortion. As to the two other taxes, 
their ambiguous incidence can be explained by the fact that they intervene at different levels. Finally, we consider the case where $\varphi=1$. In other words, the two sources of bequests cannot be distinguished: $\tau_{u}=\tau_{r}=\tau_{b}$. In that case, we have:

$$
\frac{\partial C V}{\partial \tau_{b}}=\left[\frac{\partial C V}{\partial q} \frac{1-\hat{\tau}}{z^{2}}-\frac{\partial C V}{\partial z}\right] \frac{1-\tau_{r}}{\left(1+\tau_{b}\right)^{2}} \gtrless 0 .
$$

The effect of such a tax is still ambiguous.

As to the effects of taxation on average income, we have seen (see 2.6) that they depend on whether $q \lessgtr q^{*}$.

Note that if we assume away human capital formation, all these taxes would have no effect on the capital stock, and thus on $Y$ (see Michel and Pestieau (2004)). Introducing human capital formation, it is clear that a tax on earnings discourage education and a tax on both capital income and unintended bequest induce a substitution in favor of education. Table 2 summarizes this finding.

Table 2: Welfare effect of alternative taxes

\begin{tabular}{llccccc}
\hline & Effect of an increase of & $\tau_{w}$ & $\tau_{r}$ & $\tau_{u}$ & $\tau_{x}$ & $\tau_{b}$ \\
\hline \multirow{2}{*}{ on $C V$} & & & & & & \\
on $Y$ & $q<q^{*}$ & $(-)$ & $?$ & $(-)$ & $?$ & $?$ \\
& $q>q^{*}$ & $(-)$ & $(+)$ & 0 & $(+)$ & $(+)$ \\
on SW & $q<q^{*}$ & $(+)$ & $(+)$ & 0 & $(-)$ & $(-)$ \\
& $q>q^{*}$ & $?$ & $?$ & $(+)$ & $?$ & $?$ \\
& & $(+)$ & $?$ & $(+)$ & $?$ & $?$ \\
\hline
\end{tabular}

In the case of $q>q^{*}$, raising $\tau_{w}$ enhances social welfare lowering $\mathrm{CV}$ and raising $Y$. The positive effect of $\tau_{u}$ on welfare is not surprising. All the others are ambiguous. However from Table 1 we know that welfare can always be improved by using a combination of instruments. For example, assume $q<q^{*}$. Then raising $q$ is growth-enhancing. This, however raises CV. So we need to lower $z$ to achieve $d C V<0$. Increasing $q$ and decreasing $z$ is possible by raising $\tau_{x}$ and adjusting $\tau_{w}=1-z q$ so that $d \tau w=-q d z-z d q$ given $\tau_{r}$.

To further our interpretation of tax incidence we now consider some simple cases.

We first observe the following: 
- $\pi=0$ or 1 means that there is no uncertainty on longevity and thus no accidental bequest.

- $\theta=0$ means that transferring human capital does not generate any joy of giving. This assumption is equivalent to $\mu=1$ (education has no effect on human capital).

- $\varrho=0$ means that there is no intergenerational correlation of ability.

- $\sigma_{a}^{2}=0$ means that everyone has the same capacity towards the human capital technology.

Case 1: $\theta=0$ and $\mu=1$.

In that case $k$ and $y$ don't depend on $q$ but only on $\tau_{r}$. We assume that $\varphi=1$, and thus we write:

$$
\begin{aligned}
& C V(\omega)\left[1-\frac{\beta}{\beta+\gamma}(1-\pi)\left(1-\tau_{r}\right) \alpha^{2}\right]^{2}\left[1-\left(\frac{R z}{1+\beta+\gamma}\right)^{2}\left(\pi(\beta+\gamma)^{2}+(1-\pi) \gamma^{2}\right)\right] \\
= & \pi(1-\pi)\left(\frac{\beta}{\beta+\gamma}\right)^{2} \alpha^{2} z^{2}+\sigma_{a}^{2}(1-\alpha)^{2}\left(1-\tau_{w}\right)^{2}+\sigma_{a}^{2} \frac{2 \varrho}{1+\beta+\gamma}\left(1-\tau_{w}\right)^{2} \\
& \frac{z R}{1-\varrho z R \frac{\gamma+\pi \beta}{1+\beta+\gamma}}(1-\alpha)^{2}(\gamma+\beta \pi) .
\end{aligned}
$$

We have $\frac{\partial C V}{\partial \tau_{b}}<0, \frac{\partial C V}{\partial \tau_{w}}<0, \frac{\partial C V}{\partial \tau_{r}}<0$.

Henceforth, those three taxes have a positive effect on equality. The positive role of $\tau_{w}$ depends on $\sigma_{a}^{2}>0$ (and of $\varrho$ ). The positive effect of either $\tau_{r}$ and $\tau_{b}$ is independent of $\sigma_{a}^{2}$ and $\varrho$. When $\sigma_{a}^{2}=0$, the second and third terms of the RHS of (23) vanish. This is the case studied by Michel and Pestieau (2004).

Case 2: $\pi=0, \varrho=0$

There are no accidental bequests and the source of inequality is $\sigma_{a}^{2}$. We obtain the following value for the coefficient of variation.

$$
C V(\omega)=\frac{\sigma_{a}^{2}(1-\alpha)^{2}\left(1-\tau_{w}\right)^{2}\left[(1-\theta)+\theta \mu \frac{\gamma}{1+\beta+\gamma}\right]^{2}}{\left[1-\frac{\beta}{1+\beta}\left(1-\tau_{r}\right)(\alpha+(1-\alpha) q \theta)\right]^{2}\left(1-\left(\frac{z R}{1+\beta+Y}\right)^{2} \gamma^{2}\right)}
$$


If we assume that $\frac{\partial(z R)}{\partial z}<0$ which is possible, ${ }^{4}$ then $\frac{\partial C V}{\partial \tau_{x}}>0$ and $\frac{\partial C V}{\partial \tau_{r}}>0$. If furthermore $q>q^{*}$, we have the paradoxical case of a tax on bequests that increases income inequality and decreases average income.

\section{Conclusion}

To sum up, we have studied the incidence of alternative taxes on the steadystate coefficient of variation of lifetime income and on average production in an overlapping generations model with two types of bequests, accidental and planned, and two types of planned transfers, physical and human capital.

In spite of our very simple setting (Cobb-Douglas production function and logarithmic utilities), we only get unambiguous results for the wage tax and for an estate tax restricted to accidental bequests. A tax on interest income and a tax on planned bequests have an ambiguous incidence on the coefficient of variation. Ambiguity results from the tax-induced substitution between education and intended bequest.

Finally our model rests on two key assumptions. The first is the welfare criterion used, namely the minimization of the coefficient of variation. Even though in a static framework there is a close relation between maximizing a utilitarian social welfare function and minimizing the coefficient of variation; this is not clear in a dynamic framework. We also look for the conditions under which average income is increasing and inequality is decreasing. This approach is surely more acceptable, but it is also highly demanding.

The second assumption is that of logarithmic preferences implying identical substitution between $c$ and $d$ on the one hand and between $d$ and $x$ on the other hand. Empirically it seems that the substituability between $c$ and $d$ is much lower than that between $d$ (or $c$ ) and $x$. We plan in future work to adopt a truly normative approach and to use a more general utility function.

Going back to the observed trend towards relying less and less on inheritance taxation, our paper shows that one most often can find a combination of inheritance taxes and other taxes that decreases inequality and even increases welfare.

\footnotetext{
${ }^{4}$ To obtain this result, we need $\frac{\mu(\beta+\gamma)}{1+\beta+\gamma}\left(\alpha+\beta(1-\pi)\left(1-\tau_{r}\right)(1-\alpha) \theta q\right)^{2}<\beta(1-\pi)\left(1-\tau_{r}\right)(\alpha+(1-\alpha) q \theta)^{2}$.
} 


\section{References}

[1] Becker, G. and N. Tomes, (1979), An equilibrium theory of the distributive of income and intergenerational mobility, Journal of Political Economy, 87, 1153-89.

[2] Blumkin, T. and E. Sadka, (2004), Estate taxation, Journal of Public Economics, 88, 1-21.

[3] Cremer, H. and P. Pestieau, (2005), Wealth transfer taxation: a survey of the theoretical literature, in Handbook on the Economics of Giving, Reciprocity and Altruism, L-A. Gérard-Varet, S-C. Kolm and J. Mercier Ythier (eds), North-Holland.

[4] de la Croix, D. and Ph. Michel, (2002), A Theory of Capital Accumulation. Dynamics and Policy in Overlapping Generations, Cambridge University Press, Cambridge.

[5] Gale, W.G., J.R. Hines and J. Slemrod (eds), [2001], Rethinking Estate and Gift Taxation, Brooking Institution Press, Washington.

[6] Kaplow, L., [2001], Arguments for and against estate and gift taxation, in Gale et al. (2001).

[7] Michel, Ph. and P. Pestieau, (2002), Wealth transfer taxation with both accidental and planned bequests, CORE DP 2002/59.

[8] Sen, A., (1997), On Economic Inequality, Clarendon Paperback, Oxford.

[9] Sheshinski, E. and Y. Weiss, [1981], Uncertainty and optimal social security systems, Quarterly Journal of Economics, 96, 189-206. 


\section{CESifo Working Paper Series}

(for full list see www.cesifo-group.de)

1736 Per Engström and Bertil Holmlund, Tax Evasion and Self-Employment in a High-Tax Country: Evidence from Sweden, May 2006

1737 Erkki Koskela and Mikko Puhakka, Cycles and Indeterminacy in Overlapping Generations Economies with Stone-Geary Preferences, May 2006

1738 Saku Aura and Thomas Davidoff, Supply Constraints and Housing Prices, May 2006

1739 Balázs Égert and Ronald MacDonald, Monetary Transmission Mechanism in Transition Economies: Surveying the Surveyable, June 2006

1740 Ben J. Heijdra and Ward E. Romp, Ageing and Growth in the Small Open Economy, June 2006

1741 Robert Fenge and Volker Meier, Subsidies for Wages and Infrastructure: How to Restrain Undesired Immigration, June 2006

1742 Robert S. Chirinko and Debdulal Mallick, The Elasticity of Derived Demand, Factor Substitution and Product Demand: Corrections to Hicks' Formula and Marshall's Four Rules, June 2006

1743 Harry P. Bowen, Haris Munandar and Jean-Marie Viaene, Evidence and Implications of Zipf's Law for Integrated Economies, June 2006

1744 Markku Lanne and Helmut Luetkepohl, Identifying Monetary Policy Shocks via Changes in Volatility, June 2006

1745 Timo Trimborn, Karl-Josef Koch and Thomas M. Steger, Multi-Dimensional Transitional Dynamics: A Simple Numberical Procedure, June 2006

1746 Vivek H. Dehejia and Yiagadeesen Samy, Labor Standards and Economic Integration in the European Union: An Empirical Analysis, June 2006

1747 Carlo Altavilla and Paul De Grauwe, Forecasting and Combining Competing Models of Exchange Rate Determination, June 2006

1748 Olaf Posch and Klaus Waelde, Natural Volatility, Welfare and Taxation, June 2006

1749 Christian Holzner, Volker Meier and Martin Werding, Workfare, Monitoring, and Efficiency Wages, June 2006

1750 Steven Brakman, Harry Garretsen and Charles van Marrewijk, Agglomeration and Aid, June 2006 
1751 Robert Fenge and Jakob von Weizsäcker, Mixing Bismarck and Child Pension Systems: An Optimum Taxation Approach, June 2006

1752 Helge Berger and Michael Neugart, Labor Courts, Nomination Bias, and Unemployment in Germany, June 2006

1753 Chris van Klaveren, Bernard van Praag and Henriette Maassen van den Brink, A Collective Household Model of Time Allocation - a Comparison of Native Dutch and Immigrant Households in the Netherlands, June 2006

1754 Marko Koethenbuerger, Ex-Post Redistribution in a Federation: Implications for Corrective Policy, July 2006

1755 Axel Dreher, Jan-Egbert Sturm and Heinrich Ursprung, The Impact of Globalization on the Composition of Government Expenditures: Evidence from Panel Data, July 2006

1756 Richard Schmidtke, Private Provision of a Complementary Public Good, July 2006

1757 J. Atsu Amegashie, Intentions and Social Interactions, July 2006

1758 Alessandro Balestrino, Tax Avoidance, Endogenous Social Norms, and the Comparison Income Effect, July 2006

1759 Øystein Thøgersen, Intergenerational Risk Sharing by Means of Pay-as-you-go Programs - an Investigation of Alternative Mechanisms, July 2006

1760 Pascalis Raimondos-Møller and Alan D. Woodland, Steepest Ascent Tariff Reforms, July 2006

1761 Ronald MacDonald and Cezary Wojcik, Catching-up, Inflation Differentials and Credit Booms in a Heterogeneous Monetary Union: Some Implications for EMU and new EU Member States, July 2006

1762 Robert Dur, Status-Seeking in Criminal Subcultures and the Double Dividend of ZeroTolerance, July 2006

1763 Christa Hainz, Business Groups in Emerging Markets - Financial Control and Sequential Investment, July 2006

1764 Didier Laussel and Raymond Riezman, Fixed Transport Costs and International Trade, July 2006

1765 Rafael Lalive, How do Extended Benefits Affect Unemployment Duration? A Regression Discontinuity Approach, July 2006

1766 Eric Hillebrand, Gunther Schnabl and Yasemin Ulu, Japanese Foreign Exchange Intervention and the Yen/Dollar Exchange Rate: A Simultaneous Equations Approach Using Realized Volatility, July 2006 
1767 Carsten Hefeker, EMU Enlargement, Policy Uncertainty and Economic Reforms, July 2006

1768 Giovanni Facchini and Anna Maria Mayda, Individual Attitudes towards Immigrants: Welfare-State Determinants across Countries, July 2006

1769 Maarten Bosker and Harry Garretsen, Geography Rules Too! Economic Development and the Geography of Institutions, July 2006

1770 M. Hashem Pesaran and Allan Timmermann, Testing Dependence among Serially Correlated Multi-category Variables, July 2006

1771 Juergen von Hagen and Haiping Zhang, Financial Liberalization in a Small Open Economy, August 2006

1772 Alessandro Cigno, Is there a Social Security Tax Wedge?, August 2006

1773 Peter Egger, Simon Loretz, Michael Pfaffermayr and Hannes Winner, Corporate Taxation and Multinational Activity, August 2006

1774 Jeremy S.S. Edwards, Wolfgang Eggert and Alfons J. Weichenrieder, The Measurement of Firm Ownership and its Effect on Managerial Pay, August 2006

1775 Scott Alan Carson and Thomas N. Maloney, Living Standards in Black and White: Evidence from the Heights of Ohio Prison Inmates, 1829 - 1913, August 2006

1776 Richard Schmidtke, Two-Sided Markets with Pecuniary and Participation Externalities, August 2006

1777 Ben J. Heijdra and Jenny E. Ligthart, The Transitional Dynamics of Fiscal Policy in Small Open Economies, August 2006

1778 Jay Pil Choi, How Reasonable is the 'Reasonable' Royalty Rate? Damage Rules and Probabilistic Intellectual Property Rights, August 2006

1779 Ludger Woessmann, Efficiency and Equity of European Education and Training Policies, August 2006

1780 Gregory Ponthiere, Growth, Longevity and Public Policy, August 2006

1781 Laszlo Goerke, Corporate and Personal Income Tax Declarations, August 2006

1782 Florian Englmaier, Pablo Guillén, Loreto Llorente, Sander Onderstal and Rupert Sausgruber, The Chopstick Auction: A Study of the Exposure Problem in Multi-Unit Auctions, August 2006

1783 Adam S. Posen and Daniel Popov Gould, Has EMU had any Impact on the Degree of Wage Restraint?, August 2006 
1784 Paolo M. Panteghini, A Simple Explanation for the Unfavorable Tax Treatment of Investment Costs, August 2006

1785 Alan J. Auerbach, Why have Corporate Tax Revenues Declined? Another Look, August 2006

1786 Hideshi Itoh and Hodaka Morita, Formal Contracts, Relational Contracts, and the Holdup Problem, August 2006

1787 Rafael Lalive and Alejandra Cattaneo, Social Interactions and Schooling Decisions, August 2006

1788 George Kapetanios, M. Hashem Pesaran and Takashi Yamagata, Panels with Nonstationary Multifactor Error Structures, August 2006

1789 Torben M. Andersen, Increasing Longevity and Social Security Reforms, August 2006

1790 John Whalley, Recent Regional Agreements: Why so many, why so much Variance in Form, why Coming so fast, and where are they Headed?, August 2006

1791 Sebastian G. Kessing and Kai A. Konrad, Time Consistency and Bureaucratic Budget Competition, August 2006

1792 Bertil Holmlund, Qian Liu and Oskar Nordström Skans, Mind the Gap? Estimating the Effects of Postponing Higher Education, August 2006

1793 Peter Birch Sørensen, Can Capital Income Taxes Survive? And Should They?, August 2006

1794 Michael Kosfeld, Akira Okada and Arno Riedl, Institution Formation in Public Goods Games, September 2006

1795 Marcel Gérard, Reforming the Taxation of Multijurisdictional Enterprises in Europe, a Tentative Appraisal, September 2006

1796 Louis Eeckhoudt, Béatrice Rey and Harris Schlesinger, A Good Sign for Multivariate Risk Taking, September 2006

1797 Dominique M. Gross and Nicolas Schmitt, Why do Low- and High-Skill Workers Migrate? Flow Evidence from France, September 2006

1798 Dan Bernhardt, Stefan Krasa and Mattias Polborn, Political Polarization and the Electoral Effects of Media Bias, September 2006

1799 Pierre Pestieau and Motohiro Sato, Estate Taxation with Both Accidental and Planned Bequests, September 2006 